\title{
Arrange The Factors to Improve Employees Performance in PT. XYZ by Using Fuzzy Logic Approach
}

\author{
Berlian Fatikh Mubaarok ${ }^{1}$, Bambang Syairudin ${ }^{1}$
}

\begin{abstract}
The success of a company is often seen in the company's human resources. Increased employee performance is very important for human resource management in companies that assist individual development, improve organizational performance, improve employee productivity and for the achievement of long-term objectives of the company. This research proposes is going to suggest the factors to improve the employee's motivation and performance. The pattern of these factors can be used as one of supports to improve the employee's performance in PT.XYZ. PT.XYZ hasn't "tools" yet to find and improve the employees performance. This study uses data from questionnaires with Likert scale and calculated by using relative importance index (RII) to determine the importance of fuzzy factor and logic to see the influence and prediction value of employee performance improvement level. The final result and this research get result of the possibility of employee performance improvement equal to $46,6 \%$ Factor to pay attention on employee performance is teamwork, this factor get very high valuation from employees.
\end{abstract}

Keywords-Employees Performance, RII, Fuzzy Logic.

\section{INTRODUCTION}

Every company is required to always be sustainable in the face of changing environmental dynamics, by managing any resources that exist in the company. Especially human resources which is the company's wheel drive. With the existence of highly committed resources which is one component that can improve the performance of employees or employees of the organization of the company. According to a survey conducted on construction workers it is known that productivity and employee performance is reduced by $32 \%-46,5 \%$ everyday due to lack of employee motivation factors, some due to continuous work, unemployment, lack of co-work relationship[1]. Therefore, employees are expected to maximize their responsibilities after being provided with education and training related to the implementation of their work. In addition, a comfortable working environment and motivation is basically the right of employees and obligations of the company to support the contribution of its employees in order to achieve the objectives that have been determined.

Each company must try to provide the best for every employee and also continue to provide motivation to

\footnotetext{
${ }^{1}$ Berlian Fatikh Mubaarok and Bambang Syairudin are with Departement of Master of Technology Management, Institut Teknologi Sepuluh Nopember, Surabaya, 60111, Indonesia. E-mail: berlianmubaarok@gmail.com; bambangsyairudin@gmail.com.
}

employees or employees in order to work more maximally and effectively Lack of discipline in the rules that exist in the company to make employees tend to behave in violation of working hours This makes most workers have a habit to postpone work first until the time moves beyond the limits of working hours and enter additional overtime. The normal fixed working hours are deemed ineffective for the employees, whereas during working hours they often deliberately ignore their work.

The right corporate culture which certainly will have the ability to direct the behavior of all individuals toward the ideals that become the company's goal. And improve the performance of each employee. Therefore, companies that have a good culture will have employees who are committed high cooperatively in work affairs, and always do early development and always maintain its performance.

\section{LITERATURE REVIEW}

Performance is basically a real behavior generated by each person as work performance generated by employees in accordance with its role in the company. To get a good performance from an employee in an organization must be able to provide facilities and infrastructure as a support in the completion of work. The term performance itself is the goal of the word Job Performance or Actual Performance (work achievement or actual achievement got by employees). Employee's performance is the level which employees reach job requirements. Performance is the result of an evaluation of the work performed by the employee compared to predefined criteria[2]. Performance is a result of work that has a strong relationship with the goals of organizational strategy, customer satisfaction, and provide economic contribution.

The leaders are well aware of the difference in performance between one employee and another under his supervision. Although the employees worked in the same place but their productivity is not the same. There are several opinions about the factors that affect employee performance. performance of employees is influenced by several factors, namely: Quality of work, quantity of work, knowledge of work, teamwork, creativity, and initiative[3].

Relative Importance Index (RII) is used for weighted analysis of various factors that affect employee performance. Scores for each factor obtained through the sum scores of respondents' answers, then determined the level of strength influence of each factor. 


$$
\frac{\sum w}{A N}=\frac{5 n_{5}+4 n_{4}+3 n_{3}+2 n_{2}+1 n_{1}}{5 N}
$$

$\mathrm{W}$ is the weighting given to each factor by the respondent, ranging from 1 to 5 . For example, $\mathrm{n} 1$ = medium respondent, $\mathrm{n} 4=$ high number of respondents, $\mathrm{n} 5=$ number of respondents is very high. $\mathrm{A}$ is the highest weight and $\mathrm{N}$ is the number of respondents. Relative importance index ranges from 0 to 1 .

The theory of fuzzy logic was being proposed by Prof. Lotfi Zadeh around 1965 in a paper entitled "Fuzzy Sets". That logic is true and false of boolean / conventional logic can not solve real-world problems. Fuzzy is expressed in degrees of a membership and the degree of truth. Hence something is partially true and partly wrong at the same time. Individual set theory can have membership membership with continuous value, only 0 and 1[4]. The fuzzy set is a set of elements that have varying degrees of membership in the set. The membership function is a curve showing the mapping of data input points into their membership values (called membership degrees) that have intervals between 1 and 0 . One way that can be used to obtain membership value is through a function approach.

Fuzzy Inference System (FIS) is often referred to by other terms such as fuzzy-rule based, fuzzy expert system, fuzzy modeling, fuzzy logic controller, and no fuzzy logic

controller rarely enough with fuzzy systems[5]. Fuzzy Inference System (FIS) can be used for non-exact data such as uncertainty. The system has a high degree of flexibility, tolerance to inaccuracies, can work with non-linear functionality of wide complexity, and has the ease of modification[6].

Fuzzy Logic Toolbox is a facility available in the MATLAB program to build a fuzzy logic system. Fuzzy Logic Toolbox provides Graphical User Interface (GUI) facility to make it easier to build a fuzzy system. In fuzzy modeling, it is necessary to do the variable coding stages that will be used in the research, which can be made based on the explanation or other code form. This encoding is done in order to simplify the input process of Fuzzy Toolbox MATLAB as the roles.

\section{METHODOLOGY}

For reach aim research required planning stages research activities as well as writing to be done. This stage which will be used as guidelines for research work until the completion of this research well. Following is conceptual model of research Formulating Factors to Improve Work Performance on PT.XYZ that can be seen on Figure 1.

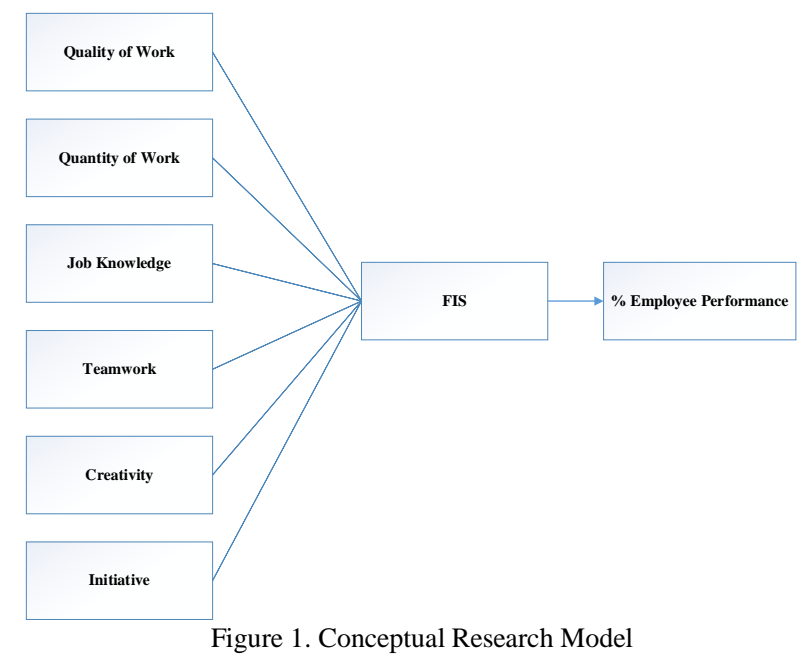

In Figure 1 above is a conceptual research model that will be done. Every factor affecting employee performance is measured using Likert scale of all respondents which are employees of PT.XYZ. After the result of Likert scale, the next step is calculating the weight of each value on Likert scale using RII, after that just modeling with the logic of each factor to know prediction of employee performance improvement PT.XYZ.

Data analysis is a step and procedure that will be done to achieve goals and get answers to problems in research. By performing a series of tests, as described. Step 1: fuzzification At this stage the determination of linguistic variables with degrees of membership. Step 2: rule evaluation This fuzzy rule evaluation stage is performed by showing the relationship between input variables and output variables called inferences. Step 3: implication method before applying the implication method, the rule's weight is determined. Every rule has a weight between 0 and 1, which is applied to the number given by the anticendent. Step 4: aggregation of all outputs because the rules are in order to make a decision. Step 5: defuzzification the input for the defuzzyfication process is a fuzzy set (aggregate output fuzzy set) and the output is a single number.

\section{RESUlT AND DisCUSSION}

The level of work motivation and employee performance can be predicted by the calculation of each factor using the calculation method of Relative Importance Index (RII) for each factor affecting employee performance. Using the equation described in equation 1 and the questionnaire result data then the RII value of all factors for improving employee performance can be determined and the result as seen in Table 1.

TABLE 1.

RII CALCULATION RESULTS

\begin{tabular}{cllcc}
\hline \hline No. & \multicolumn{1}{c}{ Factor } & \multicolumn{1}{c}{ Statement } & RII & Rank \\
\hline 1 & Teamwork & Organization like home. Everyone felt like family and helped each other. & 0,904 & 1 \\
2 & Quality of work & Work must be through, the results must be neat, and timely. & 0,864 & 2 \\
3 & Quantity of work & A lot of workload and erratic settlement time. & 0,864 & 2
\end{tabular}




\begin{tabular}{lllll}
4 & Job knowledge & Work desk suitability against background or self-ability. & 0,840 & 3 \\
5 & Creativity & This organization is cery dynamic, taking risks. & 0,760 & 4 \\
6 & Initiative & Act immediately if there is a deviation from the plan. & 0,760 & 4 \\
\hline \hline
\end{tabular}

As shown in Table 1 above, the higher value of RII calculation, the greater the importance of these factors to the employee's performance. RII calculations are discussed based on collecting data on questionnaires that have been spread on all employees PT.XYZ.

The prediction value for employee performance improvement in PT.XYZ is determined by fuzzy logic method - Fuzzy Inference System (FIS) mamdani type. Input in this study to provide predictive value of employee performance improvement taken from all factors in Table 1. the following will also explain Fuzzy FIS mamdani Logic modeling for employee performance variables. With the membership function type used triangular as illustrated in Figure 2 For example employee performance variable.

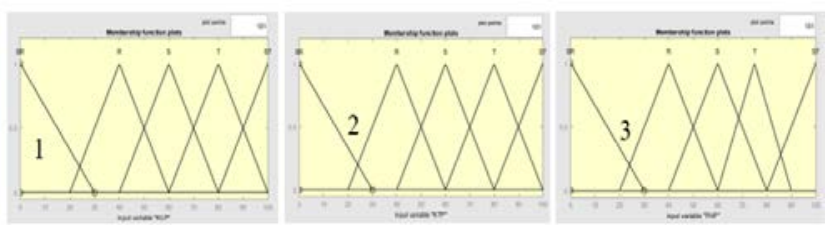

Figure 2. Membership Function of Employee Performance Input

The membership function used is one of the most popular functions to used[7]. In practice, building rules must be propered to the conditions of the research site, especially in the environmental conditions of PT.XYZ. then the authors do the discussion by giving some rules that allow to happen on PT.XYZ. Such modeling rules can be called approximate reasoning, which is an approximate reasoning term that refers to methods and methodologies that allow reasoning with improper input to get the meaning of output[8]. With approximate reasoning it is possible to model that which is not very precise or very inappropriate, in other words it is a process that makes it possible to infer the inaccurate premise, in the simplest way[9].

In this FIS mamdani modeling uses the Fuzzy Toolbox MATLAB application. The mamdani FIS method is the most commonly used blur methodology[10]. After forming fuzzy rules, then by inputting the calculation of RII from each input on the employee performance model, the predicted value of employee motivation improvement and for the predicted value possibility of employee performance improvement as shown in the rule viewer shown in picture 3 . Before making predictions of the process to be test case scenario modeling, tuning model to determine the best model. Three scenarios that have been prepared as can be seen in Table 2 below. To select the best model scenario used Mean Absolute Error (MAE) in this research[11].

$$
M A E=\frac{\sum_{1}^{n} \mid \text { Prediction Value-Actual Value } \mid}{n}
$$

Where $\mathrm{n}$ is the total of respondents, in this research were 25 respondents. With the actual value is the assesment conducted by the company.
TABLE 2.

Scenario Test Result Employee Performance Model

\begin{tabular}{ccccccc}
\hline \hline \multirow{2}{*}{ Scenario } & \multicolumn{5}{c}{ Fuzzy Output (\%) } & \multirow{2}{*}{ MAE (\%) } \\
\cline { 2 - 6 } & Que1 & Que2 & Que3 & Que4 & Que5 & \\
\hline 1 & 51,9 & 50 & 35,1 & 35,1 & 35,1 & 7 \\
2 & 48,4 & 49,4 & 35,1 & 35,1 & 35,1 & 12 \\
3 & 52,1 & 50 & 34,8 & 34,8 & 34,8 & 8 \\
\hline \hline
\end{tabular}

The first scenario (1) is modeling using triangular membership function to get the value of MAE $7 \%$ is the smallest value than the other modelling. Therefore the first model (1) is the best model to be used in the tuning model to improve the prediction accuracy.

TABLE 3.

Tuning MODEL EMPLOYEE PERFORMANCE

\begin{tabular}{|c|c|c|c|c|c|c|}
\hline \multirow{2}{*}{ Model } & \multicolumn{5}{|c|}{ Fuzzy Output (\%) } & \multirow{2}{*}{$\begin{array}{c}\text { MAE } \\
\text { (\%) }\end{array}$} \\
\hline & Que 1 & Que 2 & Que 3 & Que4 & Que 5 & \\
\hline 1 & 51,9 & 50 & 35,1 & 35,1 & 35,1 & 7 \\
\hline 1_tuning_2 & 50 & 50 & 33 & 33 & 33 & 14 \\
\hline 1_tuning_3 & 36,6 & 47,1 & 36,6 & 36,6 & 34,2 & 23 \\
\hline
\end{tabular}

Minimum MAE values were obtained after the first experiment was $7 \%$. Therefore the tuning result is then applied to the model.

Validation of this employee performance improvement prediction model is done by using MAE method. The MAE validation process is by inputting the value of the model from the 5 results of the questionnaire (A) and giving the questionnaire to the Human Resource Department leader to give a percentage of the value of each factor (B).

TABLE 4.

TeSt Results VALIDATION FUZzy LOGIC MODELLING

\begin{tabular}{ccc}
\hline \multirow{2}{*}{ Parameter } & \multicolumn{3}{c}{ Employee Performance (\%) } \\
\cline { 2 - 3 } & A & B \\
\hline Actual & 45 & 44,8 \\
Prediction & & 46,6 \\
MAE (\%) & 0,06 & 0,07 \\
\hline \hline
\end{tabular}

Based on the result of the validation that the system is said to be good if it has a MAE value closer to 0[12]. Can be said that the prediction value of the possibility of employee performance improvement is $46,6 \%$ and tested with 5 questionnaires by $45 \%$ with MAE value of $0,06 \%$, while the appraisal conducted by department head shows the prediction value of the possibility of employee performance improvement equal to $44,8 \%$ with MAE vale equal to $0,07 \%$. 


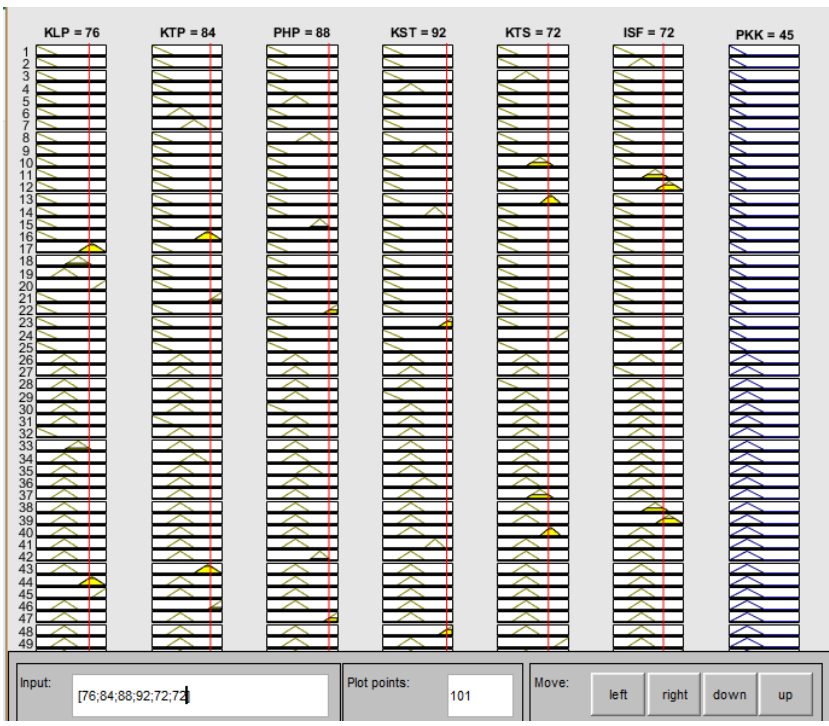

Figure 3. Rules Viewer Results of Predicted Values Possibility of

$$
\text { Employee Performance Improvement }
$$

The possibility prediction value shown in Figure 3 is the result from the point of view of the assessment given by the employee PT.XYZ, which has been formulated by the calculation of RII which the result is used as input for each model of the employee's performance. If the factors for this employee's performance are improved, it should be noted by the company to eat the predicted employee performance improvement of $46.5 \%$. In this model there is also a surface menu that shows the relationship of input to output based on the rules that have been made.

The existence of possible predicted increase in employee performance, if each factor is upgraded in accordance with the point of view of employees can help the management of PT.XYZ to detect early how the condition of the company for now and in the future in every job.

\section{SUMMARY}

Based on the results of research that has been done, then it can be drawn some conclusions, among others: Based on the formulation of RII according to employee perspective the most dominant factor on employee performance "teamwork" with a value of $90.4 \%$ and Based on the results of fuzzy modeling the value of possible increase in employee performance at PT.XYZ is at $46.6 \%$.

\section{REFERENCES}

[1] P. F. Kaming, P. O. Olomolaiye, G. D. Holt, and F. C. Harris, "What motivates construction craftsmen in developing countries? A case study of Indonesia," Build. Environ., vol. 33, no. 2-3, pp. 131141, Mar. 1998.

[2] S. P. Robbins, Organizational behavior: concepts, controversies, applications, 7th ed. London: Prentice Hall, 1996.

[3] Sugiyono, Metode Penelitian Kuantitatif, Kualitatif, dan R\&D. Bandung: Alfabeta, 2011.

[4] L. A. Zadeh, "Fuzzy sets," Inf. Control, vol. 8, no. 3, pp. 338-353, 1965.

[5] A. Naba, Belajar cepat fuzzy logic menggunakan MATLAB. Yogyakarta: Andi, 2009.

[6] S. Medina and J. Moreno, "Risk evaluation in Colombian electricity market using fuzzy logic," Energy Econ., vol. 29, no. 5, pp. 999-1009, Sep. 2007.

[7] H. Asmuni, "Fuzzy Methodologies for Automated University Timetabling Solution Construction and Evaluation," University of Nottingham, 2008.

[8] A. Khaliq and A. Ahmad, "Fuzzy Logic and Approximate Reasoning,” Blekinge Institute of Technology, 2010.

[9] S. K. Pal and D. P. Mandal, "Fuzzy logic and approximate reasoning: An overview," IETE J. Res., vol. 37, no. 5-6, pp. 548560, Sep. 1991.

[10] I. Ahmed, I. Sultana, S. K. Paul, and A. Azeem, "Employee performance evaluation: a fuzzy approach," Int. J. Product. Perform. Manag., vol. 62, no. 7, pp. 718-734, Sep. 2013.

[11] R. Sonmez, A. Ergin, and M. T. Birgonul, "Quantitative methodology for determination of cost contingency in international projects," J. Manag. Eng., vol. 23, no. 1, pp. 35-39, Jan. 2007.

[12] S. Handoyo and A. P. S. Prasojo, Sistem fuzzy terapan dengan software R. Malang: UB Press, 2017. 